\title{
Cancer-induced Defective Cytotoxic T Lymphocyte Effector Function: Another Mechanism How Antigenic Tumors Escape Immune-mediated Killing
}

\author{
Sasa Radoja ${ }^{1,2}$ and Alan B. Frey ${ }^{1}$ \\ ${ }^{1}$ Department of Cell Biology and Kaplan Cancer Center, New York University \\ School of Medicine, New York, New York, U.S.A. \\ ${ }^{2}$ The Institute of Molecular Genetics and Genetic Engineering, Belgrade, Yugoslavia \\ Accepted March 25, 2000.
}

Background: The notion that a deficit in immune cell functions permits tumor growth has received experimental support with the discovery of several different biochemical defects in T lymphocytes that infiltrate cancers. Decreased levels of enzymes involved with T-cell signal transduction have been reported by several laboratories, suggesting that tumors or host cells recruited to the tumor site actively down-regulate antitumor T-cell immune response. This permits tumor escape from immune-mediated killing. The possibility that defects in T-cell signal transduction can be reversed, which would potentially permit successful vaccination or adoptive immunotherapy, motivates renewed interest in the field. Summarizing the literature concerning tumor-induced T-cell dysfunction, we focus on the end stage of immune response to human cancer, that of defective cytotoxic $\mathrm{T}$ lymphocyte killing function. Based on the data from several laboratories, we hypothesize a biochemical mechanism that accounts for the unusual phenotype of antitumor T-cell accumulation in tumors, but with defective killing function.

\section{Introduction}

A long-standing paradox in immunology is the growth of antigenic tumor in spite of demonstrable antitumor T-cell immune response. Accumulation of $\mathrm{T}$ cells in human tumors (tumorinfiltrating lymphocytes; TIL) and production of circulating antitumor immunoglobulin G (IgG) in cancer patients show that the priming phase of antitumor immune response is functional during the relatively slow process of nascent tumor growth. Priming of antitumor T cells also occurs in experimental rodent models following injection of fast-growing transplantable tumors. $\mathrm{T}$ cells that are reactive with tumor an-

Address correspondence and reprint requests to: Dr. Alan B. Frey, Department of Cell Biology, Room MSB 690, New York University School of Medicine, 550 First Avenue, New York, New York 10016 U.S.A. Phone: 212263-8129; E-mail: freya01@popmail.med.nyu.edu tigens can be isolated from TIL, tumor-draining lymph nodes, or spleens of tumor-bearing animals (1). In transgenic strains in which tissuespecific expression of activated oncogenes initiates tumor development, tumor development occurs more slowly compared with injection of transplantable tumor and accumulation of TIL also can occur in primary tumors. In addition, in transgenic mice where $\mathrm{T}$ cells express a Tcell receptor (TCR) specific for a given nominal tumor antigen, TIL can home to and accumulate in the growing tumor after injection of tumor expressing the cognate tumor antigen (2).

In both human cancer patients and rodents bearing tumors of different histologic origin, systemic immunity is not profoundly suppressed, since tumor-bearing hosts do not show evidence of opportunistic infection and hosts mount an immune response after injec- 
tion of either model antigens or immunogenic tumor. However, inhibition of a specific antitumor immune response has been observed frequently $(3,4)$. A variety of mechanisms have been proposed to account for defective antitumor immune response, including: secretion of suppressive factors in the tumor microenvironment [for example: transforming growth factor $\beta$-1 (TGF $\beta$-1; 5,6), interleukin-10 (IL-10; 7), phosphatidyl serine (8), gangliosides (9), nitric oxide (10-12), prostaglandin $\mathrm{E}_{2}(13)$, and reactive oxygen intermediates (14)], the lack of expression of costimulatory signals on tumor cells (15), induction of regulatory $\mathrm{T}$ cells having a suppressive phenotype (16), loss of antigen presentation function in the tumor (17), loss of expression of HLA class I antigen presenting molecules in tumors (18), tumor-induced T-cell signaling defects (19), loss of tumor antigen expression (20), immunological ignorance (21), and, since many tumor antigens are either unmodified self or epitopes closely related to self, the reduction of the repertoire of potential highaffinity antitumor T-cell clones during T-cell maturation in the thymus (22).

Each of the mechanisms of tumor-induced immunesuppression has received experimental support, however, contrary findings have also been described. The existence of both supportive and contradictory evidence of the different potential tumor escape mechanisms illustrates the complex and variable nature of the immune response to tumor growth and, also, the potential difficulty of overcoming insufficient or defective antitumor immune response.

In this article, we review the evidence that human cancers are immunogenic, but that antitumor immune response is rendered dysfunctional. The mechanism by which antitumor $\mathrm{T}$ cells kill tumors in situ is not well-established. For example, antitumor $\mathrm{T}$ cells produce a variety of cytokines that can have multiple effects, including: direct cytotoxic or cytostatic effects on tumors (e.g. tumor necrosis factor- $\alpha$; TNF- $\alpha$ ) and recruitment or activation of other immune cells that are tumoricidal [e.g. granulocytemonocyte colony stimulating factor (GM-CSF) and interferon-gamma (IFN- $\gamma$ )]. In addition, certain cytokines produced by antitumor $\mathrm{T}$ cells can affect the tumor vasculature, leading to indirect tumor killing [e.g. interleukin-12 (IL-12) and IFN- $\gamma(23)]$. Direct cytolysis of the tumor by antitumor $\mathrm{T}$ cells in situ is difficult to assess, but in several models, cytolytic function of $\mathrm{T}$ cells in vitro is correlated directly with tu- moricidal effects in vivo (24-26). In addition, antitumor cytolytic $\mathrm{T}$ cells prepared from mice deficient in IFN- $\gamma$ are cytolytic in vitro, but significantly prolong survival of tumor-bearing mice. This demonstrates that IFN- $\gamma$ expression by antitumor $\mathrm{T}$ cells is not always required for antitumor activity in situ (27). Therefore, we have focused our attention on the inhibition of the cytotoxic capability of antitumor T cells. A survey of the literature led us to hypothesize that immunogenic human tumors elicit TIL indicative of stimulation of $\mathrm{T}$ cell priming by tumor antigens. However, TIL are defective in perforin- and/or serine esterase-mediated tumor lysis, thereby, permitting tumor growth in the face of the antitumor immune response. Data from murine transgenic TCR-tumor models also supports our contention that TIL are activated, but lytic function is dysfunctional in situ.

\section{Tumors Elicit Immune Response and Accumulate Infiltrating Antitumor T Cells}

Tumors have been noted to contain infiltrating cells, even prior to understanding the nature of the infiltrate. In 1929, Woglom (28) described them only as ". . . small round cells . . ." Since then, immunocytochemical analyses of human tumor specimens has shown that TIL often contain immune cells. The infiltrating immune cells comprise both the natural defense system, such as cells that do not express specific antigen receptors (macrophages, neutrophils, natural killer (NK) cells, or eosinophils), and also the adaptive immune response; wherein, $\mathrm{T}$ cells are most abundant, but considerable Bcell infiltration occurs in some tumors, especially melanoma (Table 1). The accumulation of $B$ and $T$ cells in tumor tissue strongly supports the notion of specific antigen recognition and immune response in situ. Demonstration of both circulating antitumor IgG (29-31) and TIL (32) that specifically recognize tumors in vivo and in vitro conclusively shows that human tumors are immunogenic. Furthermore, dramatic, but limited, success in two types of experimental immunotherapies strongly suggests that the $\mathrm{T}$-cell repertoire in late-stage cancer patients is not bereft of antitumor $\mathrm{T}$ cells that can react with the tumor in situ. First, the ability to isolate tumor-specific TIL, which upon expansion in vitro before adoptive transfer, causes tumor regression in vivo (33). Second, peptide vacci- 
Table 1. References for characterization of human TIL

\begin{tabular}{|c|c|c|c|c|}
\hline $\begin{array}{l}\text { Human } \\
\text { Tumor Type }\end{array}$ & Presence of TIL & $\begin{array}{c}\text { Expression of } \\
\text { Activation } \\
\text { Markers }\end{array}$ & $\begin{array}{c}\text { TIL } \\
\text { Proliferation } \\
\text { Defect }\end{array}$ & $\begin{array}{l}\text { TIL Lytic } \\
\text { Defect }\end{array}$ \\
\hline $\begin{array}{l}\text { Breast } \\
\text { carcinoma }\end{array}$ & (98) & $(59,99,100)$ & $(59,99,100)$ & $(99,100)$ \\
\hline $\begin{array}{l}\text { Prostate } \\
\text { carcinoma }\end{array}$ & $(101,102)$ & (57) & $(101)$ & (57) \\
\hline $\begin{array}{l}\text { Lung } \\
\text { carcinoma }\end{array}$ & (103) & $(99,100,104)$ & $(99,100,104)$ & $(99,100,104)$ \\
\hline $\begin{array}{l}\text { Colorectal } \\
\text { carcinoma }\end{array}$ & (85) & $(100,105)$ & $(100,105)$ & $(100,105)$ \\
\hline $\begin{array}{l}\text { Cervical } \\
\text { carcinoma }\end{array}$ & $(106,107)$ & - & (107) & (107) \\
\hline $\begin{array}{l}\text { Leukemia/ } \\
\text { lymphoma }\end{array}$ & $(108)$ & - & $(101,102)$ & (109) \\
\hline $\begin{array}{l}\text { Ovarian } \\
\text { carcinoma }\end{array}$ & (110) & $(111,112)$ & $(100)$ & $(111,112)$ \\
\hline $\begin{array}{l}\text { Renal cell } \\
\text { carcinoma }\end{array}$ & (113) & (55) & (55) & $(114)$ \\
\hline $\begin{array}{l}\text { Liver } \\
\text { carcinoma }\end{array}$ & $(115-118)$ & (119) & - & - \\
\hline Melanoma & $(120)$ & $(100)$ & $(100)$ & $(70,121)$ \\
\hline
\end{tabular}

nation of some patients results in the dramatic remission of disseminated melanoma (34). Therefore, although antitumor $\mathrm{T}$ cells expressing high-affinity TCR may be deleted from the repertoire, a sufficient number of $T$ cells exist in the periphery that can be activated by vaccination to express antitumor properties. Whether this population of $\mathrm{T}$ cells is adequate to eliminate tumors after tumor antigen vaccination remains unknown.

Although (DTH) responses to recall antigens can be depressed in cancer patients with late-stage tumors, implying defective memory responses that may limit therapeutic vaccination of patients, such defects are not profound in patients with early-stage tumors. Furthermore, the presence of circulating antitumor IgG, even in some cases decorating the primary tumor, demonstrates successful priming and expansion of the antitumor immune response and also that the tumor is accessible to humoral immune response (31). The failure of IgG reactive with tumor antigens to cause tumor lysis in situ has been postulated to result from enhanced tumor expression of inhibitors of complement function, such as CD46, CD59, and DAF (35-37), and the subject has been recently reviewed (38).
The expression of Fas Ligand (FasL) by primary tumors recently was reported by several laboratories, which at first approximation, appeared to provide another example of escape of the tumor from T-cell-mediated elimination in situ (39-43). However, two considerations suggest that this conclusion should be viewed with caution. First, the presence of viable $T$ cells in primary tumors implies that $\mathrm{T}$ cells are not eliminated at the site of tumors. If tumors induce T-cell apoptosis, T cells should be unable to be isolated from tumor tissue. However, viable non-apoptotic T cells (annexin-negative) are readily isolable from several tumor types, in some cases in significant levels. Data acquired using TdT-mediated dUTP-X nick-end labeling (TUNEL) assay of tumors in histological preparations demonstrated that there can be some apoptotic death of TIL in situ $(44,45)$. However, the extent of T-cell death in tumors is unlikely to be extensive, since within the same tumor preparations that have TUNEL $+\mathrm{T}$ cells, there are $\mathrm{T}$ cells in contact with the tumor that are not apoptotic. In addition, T-cell death is a consequence of specific antigen recognition, which is probably in the tumor microenvironment and may be the basis for the presence of apoptotic $\mathrm{T}$ cells in the tumor. Therefore, the 
presence of a limited number of apoptotic $\mathrm{T}$ cells in tumors probably indicates antigenspecific, $\mathrm{T}$ cell-tumor interaction, if not successful tumor killing. This notion is supported by the results of Zaks and colleagues (46), who showed that human melanoma TIL that expressed FasL were killed in vitro in a Fas-mediated manner that depended on specific recognition of tumor antigen.

Second, a recent report convincingly demonstrated that purported expression of FasL mRNA by primary human melanoma cells was, in fact, due to the expression of FasL transcripts by $\mathrm{T}$ cells contaminating tumor preparations (47). Expression of FasL by other primary human tumors has been reported (48), but since evaluation of the presence of contaminating $\mathrm{T}$ cells has not been rigorously made, the conclusion that a given tumor expresses FasL should be considered tentative, although FasL expressed by tumor cell lines has been reported (49-52). For example, reverse transcription polymerase chain reaction (RT-PCR) analysis of T-cell-specific transcripts derived from putative contaminating $T$ cells as was utilized by Zaks and colleagues (46) for melanoma. Whether some primary human tumors do indeed express FasL or not, the observation that viable TIL are isolable from primary tumor tissue implies that significant numbers of TIL are not apoptotic and that TIL are not effectively eliminated in situ. This point is especially noteworthy, since for several human tumors that express FasL (ovarian and renal cell carcinoma and melanoma), viable TIL can be isolated in high numbers $(44,45,53)$.

\section{TIL are Incompletely Activated in situ}

Human TIL are activated in situ, as determined by several parameters, including immunocytochemistry of pathologic specimens, analysis of Tcell cytokine gene expression by nucleic acid hybridization of tumors, assay of cytokine secretion in vitro following TIL isolation, and flow cytometry analysis after purification. However, the well-known deficit in proliferation and cytotoxic T lymphocyte (CTL) function demonstrates that TIL are anergic (54). Expression of cell surface Tcell activation antigens by immunocytochemistry of tumor histologic preparations or flow cytometry after purification from primary or metastatic tumors has shown that TIL contain a mixed phenotype of cells, since both markers in- dicative of memory and effector $\mathrm{T}$ cells are detected [expressing CD44 $4^{\text {high }}, \mathrm{CD}_{4} 5 \mathrm{RA}^{\text {low }}$, CD45RO ${ }^{\text {high }}$, and CD62 ${ }^{\text {low }}$ (55); and expressing CD28, CD69, FasL, or (HLA-DR) antigens, respectively (55-59)].

Activation antigens expressed by TIL range from "early" markers (CD69) to those expressed at later times, following activation (CD25, CD28, CD71, CD122, FasL, or DR). TIL populations can be heterogeneous in terms of expression of activation antigens, in that a variable percentage of $\mathrm{T}$ cells within a tumor express a given antigen. Of all activation markers, DR is most often expressed at high levels on a large percentage of TIL. CD25 and CD122 (the IL-2 receptor- $\alpha$ and $-\beta$ chain, respectively) are expressed least frequently in TIL populations and, when expressed, they are often only at low levels (59).

Another assessment of the activated status of TIL is the expression of cytokine mRNAs. Quiescent cells do not express significant levels of cytokine mRNAs. Following activation, typically the first cytokine mRNA expressed by naive T cells is IL- 2 and other cytokines are expressed following activation of memory (IL-2, IL-4, IL-5) or effector CTL (GM-CSF, TNF- $\alpha$, IFN- $\gamma$ ). In situ hybridization analysis of cytokine transcripts, RT-PCR analysis of tumor tissue or purified TIL, or ELISA assay of cell culture supernatants following TIL isolation has shown that, in situ or immediately upon isolation, some TIL can express cytokines other than IL-2 indicative of effector T cells $(59,60)$. As is the case for expression of cell surface activation antigens by TIL, not all cells in a given tumor express effector phase cytokines. The levels of cytokine expression, although sometimes considerable, are usually not as high as for naive $\mathrm{T}$ cells activated under idealized conditions in vitro. TIL are heterogeneous in terms of cytokine expression, since there is variability of cytokine expression in that in situ mRNA hybridization analysis can show different levels of transcripts throughout the tumor bed. In addition, there are conflicting reports as to whether TIL in a specific tumor type produce a given cytokine (58-63).

Expression of IL-2 and IL-2 receptor (CD25) proteins are not commonly detected in TIL indicative of incomplete cell activation. In cases where IL-2 is detected, the levels expressed are relatively low, compared with activated peripheral blood lymphocyte (PBL)-derived T cells (55-57,59-69). The poor expression of IL-2 receptor may be related to the low IL-2 expression, 
since IL-2 up-regulates expression of its receptor. Low-level expression of IL-2 and its high-affinity receptor indicates that, upon recruitment to and accumulation in the tumor microenvironment, TIL are either incompletely activated or, if previously expressing IL-2 and CD25, are down-regulated at the time of analysis. This conclusion is supported by the frequent observation that proliferation of freshly isolated TIL in response to TCR ligation in vitro or after exposure to exogenous IL-2 is depressed dramatically (see below).

In spite of the lack of a consensus concerning which cytokines are produced in TIL and at what levels, several conclusions may be drawn from these analyses. First, the expression of activation markers on TIL, as analyzed in situ or immediately after isolation, strongly indicates previous priming and recruitment to the tumor. Second, T-cell cytokine mRNAs have been observed in tumor tissue by in situ hybridization analysis and also in freshly isolated TIL without deliberate activation in vitro, which implies that TIL are activated in situ and are expressing at least one effector phase function. Since the levels of TIL cytokines are variable and also modest compared with CTL lines or T-cell clones, it is possible that TIL are heterogeneous in terms of cytokine expressing. This results in some $\mathrm{T}$ cells in a population producing a given cytokine at the time of assay, but others are not. The notion that only a subset of TIL are actively transcribing cytokine genes is in keeping with the abovementioned observations that TIL are heterogeneous in expression of activation antigens.

\section{TIL are Deficient in Proliferative Response and CTL Function in vitro}

TIL have been analyzed extensively for proliferative responsiveness to TCR ligation (or mitogen stimulation) in vitro, permitting the conclusion that TIL are deficient in proliferative response (Table $1 ; 32$ ). In comparison to proliferation of peripheral blood T cells, TIL also have a clonogenic deficit, suggesting that the frequency of TIL that can proliferate is low (32). As for expression of activation antigens and cytokines, TIL are heterogeneous for proliferative deficit, compared with autologous PBL, such that TIL from some tumors are more inhibited than others. This may be due to variability in TIL purity, which because some tumors express secreted products capable of in- hibiting T-cell activation (e.g. TGF- $\beta$ ), might reflect active inhibition of proliferation in vitro by contaminating tumor cells. The extent of depressed proliferation varies among different TIL preparations, but a consistent observation is that isolated TIL do not incorporate tritiated thymidine in vitro to any appreciable extent without activation showing that TIL are not in $S$ phase at the time of isolation. The proliferative deficit in TIL is consistent with the observation that IL-2 expression is severely depressed. Collectively the data suggests that the majority of $\mathrm{T}$ cells in a TIL population are nonresponsive to TCR ligation, although perhaps, a minor population of cells can incorporate thymidine.

Similarly, TIL are deficient in CTL function. Freshly isolated TIL show very low levels of cytotoxicity towards either autologous tumor or HLA-matched tumor cell lines (Table 1; 54). In addition, assay of TIL CTL function by redirected cytolysis assay of irrelevant targets shows that the lytic deficit is not antigen-specific. In order to develop antitumor cytolytic function after purification, several cycles of in vitro culture in the presence of IL-2 usually is required $(70,71)$. Analysis of the biochemical basis of deficient CTL function has not been made conclusively, but analysis of serine esterase transcripts suggests that transcription of granzyme B is diminished in TIL (72). By implication, this observation suggests that TIL may be defective in lytic function because of either enhanced granzyme mRNA degradation or a failure to induce transcription of mRNAs encoding granzymes. Quantitation of accumulated perforin or serine esterase proteins on a per cell basis, compared with CTL clones, has not been made, so the possibility that TIL CTL activity is reduced because of a failure to release pre-formed lytic granules cannot be made definitively (see below).

The CTL lytic deficit has also been described in several transgenic TCR mouse models $(2,73)$. TIL expressing a TCR reactive with a defined major histocompatibility complex (MHC) class Irestricted model tumor antigen were recovered from tumors, but demonstrated poor lysis of tumor cells in vitro. The expression of effectorphase cytokines in these TIL was not defined, but was anticipated to be depressed, relative to spleen T cells. Recently Prevost-Blondel and colleagues (2) reported that the lytic capability of TIL in one model was intact. However, the killing assay utilized in these experiments was "long-term," such as after overnight TIL co- 
culture with labeled tumor targets. We suggest that TIL in that model kill targets by Fasmediated lysis for two reasons. Firstly, FasL is up-regulated in $\mathrm{T}$ cells upon activation in less than $4 \mathrm{hr}$ (which occurs in long-term killing assays, even in primary mixed lymphocyte reaction (MLR); S. Radoja and M. Saio, unpublished observations). Furthermore, granzyme-mediated target lysis occurs in $\mathbf{3 - 5} \mathbf{~ h r}$, as is typically seen in MLR cytolysis assays. Therefore, the requirement for overnight contact with target cells in order to detect cytolysis implies serine esterase-mediated killing is not occurring. Secondly, TIL recovered from tumors expressed high levels of FasL (2), a finding that our laboratory has also observed in several murine tumor models (S. Radoja and M. Saio, unpublished observations). Therefore, the conclusion reached by Prevost-Blondel and colleagues (2) that TIL are highly lytic should be interpreted with the proviso that lysis in this model is Fas-mediated; whereas, serine esterasemediated tumor cytolysis is likely to be the major mechanism of CTL killing of tumors. This conclusion is supported by the description that FasL $^{+}$prostate tumor cell lines are resistant to Fas-mediated killing in vitro (74). In addition, the recent report that TIL lysis of glioma and melanoma cells in vitro was calcium-dependent and not inhibited by anti-Fas antibody implies a perforin-mediated mechanism of lysis (75).

\section{TIL Defects are Transitory}

Several reports have shown that TIL recover proliferative and lytic defects after purification from tumor cells and other infiltrating cell types [Table 1 and (32)]. One possible explanation is that a minor population of TIL recovers from the proliferative defect and expands during in vitro culture; whereas, most TIL remain permanently dysfunctional. However, we think that explanation unlikely because dramatic recovery of function is often achieved with celerity after purification, in some cases after only 1-2 days (59). Also, recovery of perforin-mediated lytic function in murine TIL is significant in as little as $6 \mathrm{hr}$ following purification (S. Radoja, unpublished observation). The ability to derive human T-cell clones lytic for cognate tumor cells shows that TIL contain antitumor $\mathrm{T}$ cells that recover killing function and form the basis for tumor antigen identification by expression gene cloning. This implies that either the tumor itself, or host cells present in the tumor, induce the transitory proliferative and lytic defects in TIL. Recovery of TIL function can be achieved by culture in phorbol myristate acetate (PMA) plus ionomycin; whereas, stimulation of TIL by TCR ligation is often ineffective (54). This observation is in agreement with the notion that TIL have a block in some component(s) of the proximal TCR signaling pathway (e.g. TCR $\zeta$ ). The rapid recovery of TIL function suggests that the anergic phenotype of TIL is a transitory state, rather than an acquired permanent deficit. The biochemical basis for tumor-induced TIL anergy is unknown and its understanding is a major goal of the field. As mentioned above, there are several candidate molecules secreted by tumors or infiltrating host cells that are known to inhibit T-cell proliferation, which may be responsible for induction and maintenance of TIL anergy. The mechanisms of action, however, are not understood fully. In addition, there are other possible mechanisms for induction of TIL anergy that may include a requirement for cell-tocell contact. We suggest one such model below.

\section{A Model to Explain TIL Anergy and Defect Lytic Function}

We hypothesize that immunogenic tumors escape $\mathrm{T}$ cell killing because TIL receive an abortive apoptotic signal, which inactivates TCRmediated signal transduction and, therein, renders them anergic. In this scenario, induction of apoptosis results in caspase activation. This, in turn, degrades TCR $\zeta$, thereby, inhibiting TCRmediated signal transduction. However, instead of inexorable progression to cell death, a downstream step(s) in the apoptotic pathway is blocked, preventing TIL death. TIL, in which apoptosis has been initiated, cannot transmit TCR-mediated signals upon antigen recognition and, thus, remain in $G_{0} / G_{1}$ segment of the cell cycle. Upon removal of the proapoptotic signal, TIL can recover expression of TCR $\zeta$ and enter the cell cycle, if appropriately stimulated with antigen. This model explains the observed anergic status of TIL and the ability of purified TIL to recover from tumor-induced TIL unresponsiveness, is partially supported by published data, and has aspects that can be directly tested.

This hypothesis is based upon the observations that TIL express both Fas and FasL, and are simultaneously deficient of the ability to respond to stimulation via the TCR (shown 
schematically in Figure 1). We propose that, upon recruitment to and accumulation in tumors, TIL receive an apoptotic signal from either $\mathrm{FasL}^{+}$TIL or from other FasL ${ }^{+}$cells in the tumor microenvironment, which may include the tumor itself or monocyte-derived cells.
Alternatively, another host cell type recruited to the tumor environment may express another molecule capable of inducing apoptosis, possibly TNF- $\alpha$. Transmission of the apoptotic signal to TIL initially causes activation of a caspase (step 1), probably caspase 8 (76). Positioned

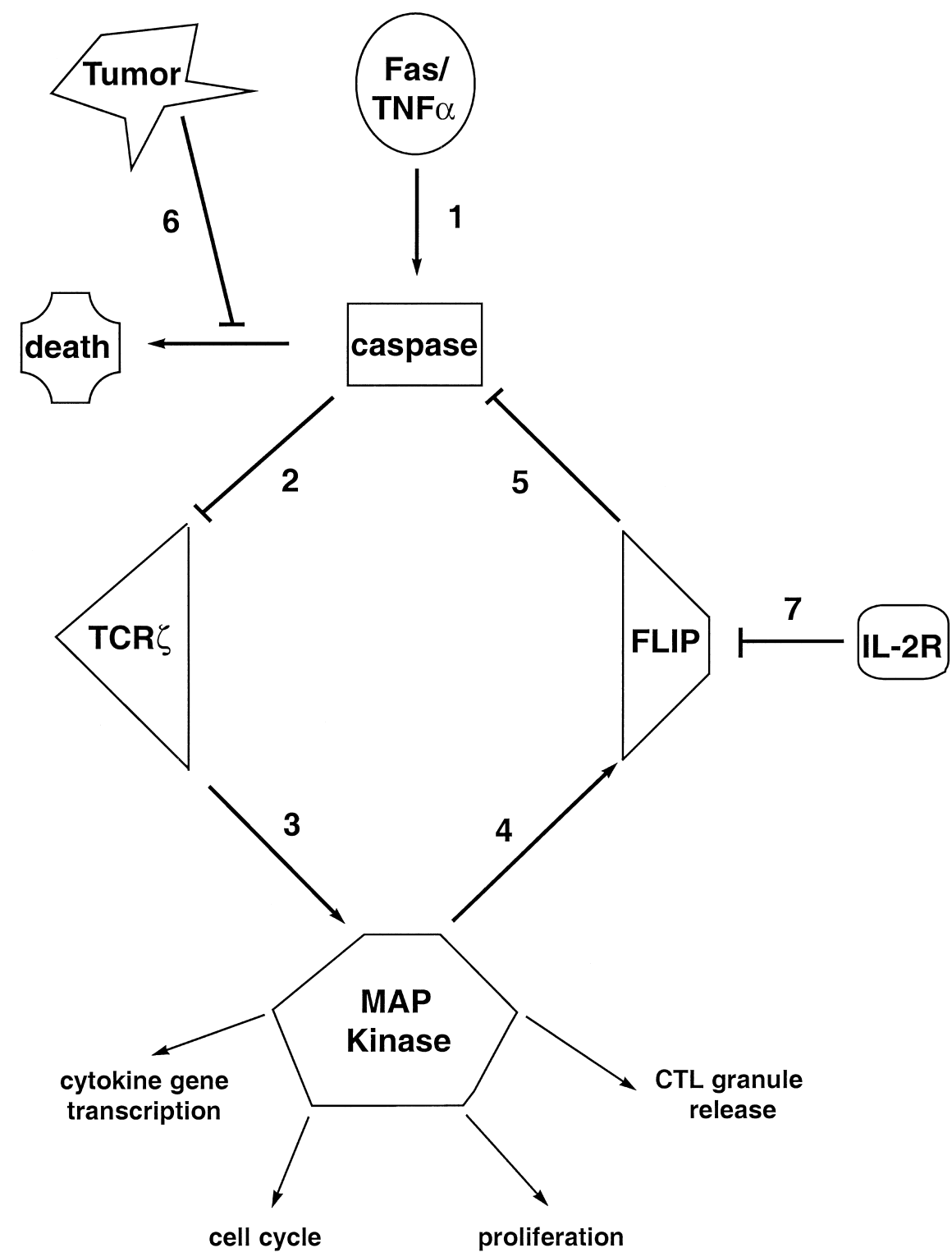

Fig. 1. A model of TIL anergy. The anergic state is maintained by low levels of FLICE inhibitory protein (FLIP). Arrows indicate steps in normal $\mathrm{T}$ cells that are sequential activation events. Blocks in the anergy pathway are indicated by blunted lines (steps 2, 5, 6, and 7). Step 1 is the activation of caspase by induction of the Fas (or TNF- $\alpha$ ) pathway. Apoptosis can be activated by any cell in the tumor environment that expresses FasL or TNF- $\alpha$; tumor, activated macrophages, or TIL. Step 2 is cleavage of TCR $\zeta$ by activated effector caspases. Step 3 is the failure to activate MAP kinase, because of inactivated TCR $\zeta$. Failure to activate MAP kinase results in down-regulated cytokine transcription, loss of proliferative response to TCR ligation, failure to transit the cell cycle, and loss of effector phase CTL function, especially granule release. Step 4 is downregulation of FLIP, since MAP kinase is inactivated. Step 5 is up-regulation of caspases in response to decreased FLIP levels. Step 6 is a block in production of death substrates putatively induced by the tumor. Step 7 is the involvement of IL-2 receptormediated signaling in maintenance of FLIP levels. TNF, tumor necrosis factor; TCR $\zeta$, T-cell receptor zeta; IL-2R, interleukin-2 receptor; MAP, mitogenactivated protein; CTL, cytotoxic T lymphocyte. 
at the top of the hierarchy of apoptotic signal transduction, caspase 8 has several potential targets, especially other enzymes in the apoptosis pathway. The demonstration that $\mathrm{TCR} \zeta$ is proteolyzed in vitro by activated caspase 3 was recently made by Gastman and colleagues (77), which provides an essential connection bet ween putative activation of Fas-mediated apoptosis and down-regulation of TCR-mediated TIL signal transduction (step 2). In additional studies, Rabinowich and colleagues (44) showed that TCR $\zeta$ was down-regulated in T cells derived from ovarian carcinoma patients, coincident with induction of DNA fragmentation upon in vitro coculture with ovarian carcinoma cells, and that TCR $\zeta$ loss was prevented by inclusion of caspase inhibitors. Furthermore, this key point is indirectly supported by findings from several laboratories that the level of TCR $\zeta$ protein is severely diminished in human TIL $(54,67,78-84)$. The specific caspase that degrades $\operatorname{TCR} \zeta$ in situ is not yet known, but the essential postulate is that, in TIL, caspases are activated and, as a direct result, TCR-mediated signal transduction is down-regulated.

In addition to the proliferative defect in TIL, which available evidence suggests is induced by degradation of TCR $\zeta$, CTL perforin- and/or serine esterase-mediated cytolysis function is also commonly defective (step 3). Potentially, there are three steps in CTL lytic function that could be subjected to tumor-induced downregulation: (1) transcription of perforin/serine esterase mRNAs, (2) translation of lytic enzyme mRNAs and, (3) assembly into granules, or, since lytic enzymes are stored preformed in cytoplasmic granules, activation-induced granule release. There has been a recent report that expression of mRNA encoding granzyme $B$ is reduced in TIL, implying that cytolytic function is reduced in TIL, because of a failure to transcribe this key enzyme necessary for lytic function (72). However, there are several reports that perforin and granzyme proteins are detected in histologic preparations of renal cell and colorectal carcinomas $(85,86)$. The presence of lytic proteins in TIL in tumor specimens argues against a transcriptional block in lytic enzyme production, although transcriptional down-regulation of these effector phase-specific enzymes in TIL may be a function of the particular tumor or stage of growth. If the presence of granzymes and perforin in TIL can be generalized to other tumors, then the block in CTL lytic function is predicted to be due to inhibition of release of lytic granules. In support of this contention, Berg et al. (87) reported that degranulation of CTL required sustained TCR-mediated signal transduction. Therefore, the deficient TCR-mediated proliferative responses in TIL, suggested to be due to decreased TCR $\zeta$ levels, implies that TIL are unable to activate a downstream kinase that is required for CTL granule release (88).

A regulator of caspase activation has been described [(FLICE)-Inhibitory Protein, or 'FLIP'], which competitively inhibits binding of procaspase 8 to an adapter molecule (Fasassociated death domain-containing protein, or FADD). That molecule, in turn, interacts with Fas, thereby, preventing transmission of the Fas apoptotic signal $(89,90)$. In freshly activated T cells, FLIP levels are high, which prevents activation of endogenously expressed Fas and apoptosis. However, if $\mathrm{T}$ cells are re-stimulated following 3 days of activation in vitro, FLIP expression is suppressed. It has been reported that IL-2 suppresses transcription of FLIP, which competitively inhibits the binding of caspase- 8 to Fas adapter molecule FADD, thereby inhibiting Fas signaling (90). Our model proposes that, similar to $\mathrm{T}$ cells activated in vitro by the scheme of Refaeli and colleagues (90), signal transduction through the IL-2 receptor occurs only immediately subsequent to recruitment of TIL to the tumor that initiates down-regulation of FLIP (step 7). At later stages, after arrival in the tumor, regulation of FLIP expression is IL-2-independent, since FLIP levels are down-regulated due to inability of mitogen-2 activated protein (MAP) kinase to up-regulate FLIP transcription. In response to decreased MAP kinase activation, we postulate that reduced levels of FLIP (step 4), in turn, enhances caspase activation (step 5) (90). The activation of caspase then reinforces the anergic state by maintaining the degradation of TCR $\zeta$ (step 2). As long as levels of FLIP are low, caspase will be activated, thereby, maintaining the anergic cycle. This scenario predicts that if caspase activation is blocked, for example, by peptide inhibitors as mentioned above, then TCR $\zeta$ levels should recover, in spite of low levels of FLIP, and TCR-mediated signal transduction should be restored. This possibility is indirectly supported by the data of Zaks and colleagues (46), who showed that activation-induced cell death (AICD) of TIL was prevented by tripeptide inhibitors of caspase and, also, by the aforementioned data from Rabinowich and colleagues (44). 
TIL that are blocked in TCR-mediated signal transduction are unable to transit the cell cycle, thereby, remaining in $G_{0} / G$. They have other defects as a result of inactive MAP kinase (step 3), but the various consequences of a MAP kinase block do not account for the failure of TIL death after caspase activation. Therefore, we propose that, instead of rapid induction of TIL cell death, transmission of a downstream apoptotic signal is blocked and TIL death is prevented (step 6). This suggestion is supported by the observations that freshly isolated TIL do not express cell-surface phosphatidyl serine at levels greater than non-TIL T cells or have fragmented DNA (45). The biochemical basis for the block in apoptosis is unknown, but if activated caspase is responsible for TCR $\zeta$ cleavage as the data of Rabinowich and colleagues (44) implies, it is anticipated that the block in cell death lies after caspase activation and before the production of death substrates (91). One possibility is that the source of the death blockade is the tumor itself, since purified TIL placed into culture rapidly die by apoptosis (S. Radoja, unpublished observations).

Maintenance of the anergic state of TIL could also be explained by IL-2 receptormediated down-regulation of FLIP (step 7). Accordingly, the presence of IL-2 at the site of the tumor would lead to FLIP down-regulation, allowing Fas-induced caspase activation and TCR $\zeta$-chain degradation. However, as considered above, we think this possibility is unlikely, since expression of IL-2 and IL-2 receptor (CD25) proteins are not commonly detected in TIL. Our model proposes that IL-2 initiates down-regulation of FLIP in TIL upon their initial recruitment to the tumor. At some point after accumulation in the tumor, IL-2 levels decrease, because of decreased MAP kinase that is required for IL-2 production. At this point regulation of FLIP expression in TIL is IL-2independent, since FLIP are maintained at low levels, due to the failure to transmit TCRmediated signals, which are mediated by MAP kinase. MAP kinase has been shown to be required for induction of FLIP expression (92).

\section{Conclusions and Unanswered Questions}

Several questions are raised by our hypothesis, some of which can be directly tested. A key tenet of our hypothesis is that the apop- totic pathway is activated in TIL via Fas or TNF- $\alpha$ receptor, which results in caspase activation, which in turn, is responsible for proteolysis of TCR $\zeta$. This can be indirectly supported by the demonstration that caspases in TIL are activated by immunoblotting TIL protein extracts with antibodies that are reactive with the activated forms of different caspases. In order to solidify the connection between Fas activation and TCR $\zeta$ degradation, proteolysis of TCR $\zeta$ should result from deliberate Fas activation. This might be demonstrated using nontumor TIL CTL clones or MLR lines, in which TCR $\zeta$ should be degraded upon Fas activation in vitro and should be prevented by caspase inhibitors. Apoptosis can also be induced by activation of TNF-related apoptosisinducing ligand (TRAIL) receptor or TNF- $\alpha$ receptor (93). Cell death induced by TRAIL also involves activation of caspases (94), so if the apoptotic signal is delivered to TIL via TRAIL instead of Fas, TIL dysfunction would still be dependent upon caspase activation. This, in turn, results in the down-regulation of TCR $\zeta$.

Another postulate proposed to explain defective CTL function in TIL is that perforin and/or serine esterases are synthesized, but are unable to be released from CTL, because of defective TCR-mediated signal transduction. Since an activation signal through MAP kinase is required for perforin mobilization (88) or degranulation (87), MAP kinase is anticipated to exist in the inactive form. This can be tested by performing kinase assays programmed with immunoprecipitates of MAP kinase from TIL protein extracts that are prepared from either freshly isolated TIL or after reactivation in vitro. However, there are several reports that CTL effector phase function is independent of MAP kinase (95-97). Our model postulates a role for defective MAP kinase activation, because of the central role of MAP kinase in downstream TCR-mediated signal transduction, including proliferation and transit of the cell cycle. If CTL granule release is not controlled exclusively by MAP kinase and another kinase performs that function, our hypothesis would be modified to include the inactivation of protein kinase $\mathrm{C}$ (PKC) or phosphatidylinositol-3 (PI3) kinase as a consequence of caspase activation and TCR $\zeta$ degradation. This can be similarly tested, as for MAP kinase, by analysis of PKC or PI3 kinase activity in TIL. Since activation of PKC or PI3 kinase requires activated TCR $\zeta$, recovery of downstream effector phase functions in TIL 
should be recovered via activation by (PHA) plus ionomycin, which is predicted to overcome proximal TCR signaling defects.

A consequence of our hypothesis that apoptosis is initiated in TIL, but apoptotic death is prevented, is that TIL should be "primed" to die in situ. In support of this contention is the observation that, when purified and assayed in vitro, human TIL demonstrate a high sensitivity to AICD (45). We also have observed enhanced AICD sensitivity in murine TIL, which is reversible by inclusion of blocking Fas antibody (S. Radoja, unpublished observations).

A major unanswered question concerns the nature of the putative block in TIL apoptosis. If caspase is activated in TIL, but TIL do not have fragmented DNA or express phosphatidyl serine on the $T$ cell surface, then is production of death substrates expected to be inhibited? The demonstration in TIL possessing activated caspases (and proteolyzed TCR $\zeta$ ) that death substrates [e.g., polyADPribose polymerase, DNA fragmentation factor, gelsolin, or nucleolamin] are not produced/activated would support the supposition that there is a block in apoptosis signaling. An alternative explanation, which would obviate the necessity of a block in apoptosis, is that the TCR $\zeta$ may be highly sensitive to caspase-mediated cleavage, producing activated caspase levels that could be produced in TIL, which result in TCR $\zeta$ cleavage, but are insufficient to produce cell death. Yet another possibility is that in TIL TCR $\zeta$ is cleaved, not by an activated effector caspase, but by another protease altogether and that the cleavage of TCR $\zeta$ in vitro by caspase is a "red herring." The presence of both activated caspases in TIL and intact TCR $\zeta$ following treatment of TIL with inhibitors of specific caspases would argue against this possibility.

The rapid recovery of TIL function following purification is explained in this model by the recovery of TCR $\zeta$ levels, once the Fas-inducing signal is removed (delivered by tumor cells or host cells in the tumor microenvironment). Signal transduction via the TCR could resume. In addition, since the caspase blockade would also be lost upon TIL purification, thereby permitting apoptosis, apoptotic cell death should be recovered. The enhanced sensitivity of purified TIL to AICD in vitro, mentioned above, is compatible with this notion.

\section{Acknowledgments}

Research in our laboratory is supported by NIH grants CA57797 and CA83687. We thank Stanislav Vukmanovic for editorial comments.

\section{References}

1. Velders MP, Schreiber H, Kast WM. (1998) Active immunization against cancer cells: impediments and advances. Semin. Oncol. 25: 697706.

2. Prevost-Blondel A, Zimmermann C, Stemmer C, Kulmburg P, Rosenthal FM, Pircher H. (1998) Tumor-infiltrating lymphocytes exhibiting high ex vivo cytolytic activity fail to prevent murine melanoma tumor growth in vivo. J. Immunol. 161: 2187-2194.

3. Sogn JA. (1998) Tumor immunology: the glass is half full. Immunity 9: 757-763.

4. Finke J, Ferrone S, Frey A, Mufson A, Ochoa A. (1999) Where have all the T cells gone? Mechanisms of immune evasion by tumors. Immunol. Today 20: 158-160.

5. Inge TH, Hoover SK, Susskind BM, Barrett SK, Bear HD. (1992) Inhibition of tumorspecific cytotoxic T-lymphocyte responses by transforming growth factor $\beta-1$. Cancer Res. 52: 1386-1392.

6. Ruffini PA, Rivoltini L, Silvani A, Boiardi A, Parmiani G. (1993) Factors, including transforming growth factor $\beta$, released in the glioblastoma residual cavity, impair activity of adherent lymphokine-activated killer cells. Cancer Immunol. Immunother. 36: 409-416.

7. Matsuda M, Salazar F, Petersson $M$, et al. (1994) Interleukin 10 pretreatment protects target cells from tumor- and allo-specific cytotoxic $\mathrm{T}$ cells and downregulates HLA class I expression. J. Exp. Med. 180: 2371-2376.

8. Cheng X, Lopez DM. (1998) $\mathrm{CD}^{+}{ }^{+}$, but not $\mathrm{CD}^{+}, \mathrm{T}$ cells from mammary tumor-bearing mice have a down-regulated production of IFN- $\gamma$ : role of phosphatidyl serine. J. Immunol. 160: 2735-2741.

9. Uzzo RG, Rayman P, Kolenko V, et al. (1999) Renal cell carcinoma-derived gangliosides suppress nuclear factor- $\kappa \mathrm{B}$ activation in $\mathrm{T}$ cells. J. Clin. Invest. 104: 769-776.

10. Alleva DG, Burger CJ, Elgert KD. (1994) Tumor-induced regulation of suppressor macrophage nitric oxide and TNF- $\alpha$ production. Role of tumor-derived IL-10, TGF- $\beta$, and prostaglandin E2. J. Immunol. 153: 1674-1686.

11. Lejeune $\mathrm{P}$, Lagadec $\mathrm{P}$, Onier N, Pinard D, Ohshima H, Jeannin JF. (1994) Nitric oxide involvement in tumor-induced immunosuppression. J. Immunol. 152: 5077-5083.

12. Young MR, Wright MA, Matthews JP, Malik I, Prechel M. (1996) Suppression of T cell pro- 
liferation by tumor-induced granulocytemacrophage progenitor cells producing transforming growth factor- $\beta$ and nitric oxide. J. Immunol. 156: 1916-1922.

13. Linnemeyer PA, Pollack SB. (1993) Prostaglandin E2-induced changes in the phenotype, morphology, and lytic activity of IL-2activated natural killer cells. J. Immunol. 150: 3747-3754.

14. Kono K, Salazar-Onfray F, Petersson M, et al. (1996) Hydrogen peroxide secreted by tumorderived macrophages down-modulates signaltransducing $\zeta$ molecules and inhibits tumorspecific $T$ cell- and natural killer cell-mediated cytotoxicity. Eur. J. Immunol. 26: 1308-1313.

15. Melero I, Bach N, Chen L. (1997) Costimulation, tolerance and ignorance of cytolytic $\mathrm{T}$ lymphocytes in immune responses to tumor antigens. Life Sci. 60: 2035-2041.

16. North R, Awwad M. (1990) Elimination of cycling $\mathrm{CD}^{+}{ }^{+}$suppressor $\mathrm{T}$ cells with an antimitotic drug releases non-cycling $\mathrm{CD}^{+} \mathrm{T}$ cells to cause regression of an advanced lymphoma. Immunol. 71: 90-95.

17. Kaklamanis L, Hill A. ( 1992) MHC loss in colorectal tumors: evidence for immunoselection. Cancer Surveys 13: 155-171.

18. Hicklin DJ, Marincola FM, Ferrone S. (1999) HLA class I antigen downregulation in human cancers: T-cell immunotherapy revives an old story. Mol. Med. Today 5: 178-186.

19. Morford L, Elliot L, Carlson S, Brooks W, Roszman T. (1997) T cell receptor-mediated signaling is defective in $\mathrm{T}$ cells obtained from patients with primary intracranial tumors. J. Immunol. 159: 4415-4425.

20. Maeurer MJ, Gollin SM, Martin D, et al. (1996) Tumor escape from immune recognition: lethal recurrent melanoma in a patient associated with downregulation of the peptide transporter protein TAP-1 and loss of expression of the immunodominant MART-1/MelanA antigen. J. Clin. Invest. 98: 1633-1641.

21. Ochsenbein AF, Klenerman P, Karrer U, et al. (1999) Immune surveillance against a solid tumor fails because of immunological ignorance. Proc. Natl. Acad. Sci. USA 96: 2233-2238.

22. Targoni OS, Lehmann PV. (1998) Endogenous myelin basic protein inactivates the high avidity $\mathrm{T}$ cell repertoire. J. Exp. Med. 187: 20552063.

23. Voest EE, Kenyon BM, O'Reilly MS, Truitt G, $\mathrm{D}^{\prime}$ Amato RJ, Folkman J. (1995) Inhibition of angiogenesis in vivo by interleukin 12 [see comments]. J. Natl. Cancer Inst. 87: 581-586.

24. Mokyr MB, Rubin M, Newell KA, Prokhorova A, Bluestone JA. (1993) Involvement of TCR$\mathrm{V} \beta 8.3^{+}$cells in the cure of mice bearing a large MOPC-315 tumor by low dose melphalan. J. Immunol. 151: 4838-4846.
25. Ma D, Alizadeh H, Comerford SA, et al. (1994) Rejection of intraocular tumors from transgenic mice by tumor-infiltrating lymphocytes. Curr. Eye Res. 13: 361-369.

26. Evans R, Kamdar SJ, Duffy TM, Krupke DM, Fuller JA, Dudley ME. (1995) The therapeutic efficacy of murine anti-tumor $\mathrm{T}$ cells: freshly isolated $\mathrm{T}$ cells are more therapeutic than $\mathrm{T}$ cells expanded in vitro. Anticancer Res. 15: 441-447.

27. Dobrzanski MJ, Reome JB, Dutton RW. (2000) Type 1 and type $2 \mathrm{CD}^{+}$effector $\mathrm{T}$ cell subpopulations promote long-term tumor immunity and protection to progressively growing tumor. J. Immunol. 164: 916-925.

28. Woglom WH. (1929) Immunity to transplantable tumors. Cancer Rev. 4: 129-2 14.

29. Disis ML, Calenoff E, McLaughlin G, et al. (1994) Existent T-cell and antibody immunity to HER-2/neu protein in patients with breast cancer. Cancer Res. 54: 16-20.

30. Kotera Y, Fontenot JD, Pecher G, Metzgar RS, Finn OJ. (1994) Humoral immunity against a tandem repeat epitope of human mucin MUC1 in sera from breast, pancreatic, and colon cancer patients. Cancer Res. 54: 2856-2860.

31. Stockert E, Jager E, Chen YT, et al. (1998) A survey of the humoral immune response of cancer patients to a panel of human tumor antigens. J. Exp. Med. 187: 1349-1354.

32. Whiteside TL. (1993). Tumor-infiltrating lymphocytes in human malignancies. Medical Intelligence Unit. CRC Press, Boca Raton, FL. pp. 1-110.

33. Rosenberg SA. (1990) Adoptive immunotherapy for cancer. Sci. Am. 262: 62-69.

34. Rosenberg SA, Yang JC, Schwartzentruber DJ, et al. (1998) Immunologic and therapeutic evaluation of a synthetic peptide vaccine for the treatment of patients with metastatic melanoma. Nat. Med. 4: 321-327.

35. Liszewski MK, Post TW, Atkinson JP. (1991) Membrane cofactor protein (MCP or CD46): newest member of the regulators of complement activation gene cluster. Annu. Rev. Immunol. 9: 431-455.

36. Bjorge L, Hakulinen J, Wahlstrom T, Matre R, Meri S. (1997) Complement-regulatory proteins in ovarian malignancies. Int. J. Cancer 70: 14-25.

37. Yu J, Caragine T, Chen S, Morgan BP, Frey AB, Tomlinson S. (1999) Protection of human breast cancer cells from complement-mediated lysis by expression of heterologous CD59. Clin. Exp. Immunol. 115: 13-18.

38. Maio M, Brasoveanu LI, Coral S, et al. (1998) Structure, distribution, and functional role of protectin (CD59) in complement-susceptibility and in immunotherapy of human malignancies (Review). Int. J. Oncol. 13: 305-318.

39. Hahne M, Rimoldi D, Schoter M, et al. (1996) Melanoma cell expression of Fas (Apo- 
1/CD95) ligand: implications for tumor immune escape. Science 274: 1363-1366.

40. Walker PR, Saas P, Dietrich PY. (1997) Role of Fas ligand (CD95L) in immune escape: the tumor cell strikes back. J. Immunol. 158: $4521-$ 4524.

41. Walker PR, Saas P, Dietrich PY. (1998) Tumor expression of Fas ligand (CD95L) and the consequences. Curr. Opin. Immunol. 10: 564-572.

42. Bennett MW, O'Connell J, O'Sullivan GC, et al. (1998) The Fas counterattack in vivo: apoptotic depletion of tumor-infiltrating lymphocytes associated with Fas ligand expression by human esophageal carcinoma. J. Immunol. 160: 5669-5675.

43. Cardi G, Heaney JA, Schned AR, Ernstoff MS. (1998) Expression of Fas(APO-1/CD95) in tumor-infiltrating and peripheral blood lymphocytes in patients with renal cell carcinoma. Cancer Res. 58: 2078-2080.

44. Rabinowich $H$, Reichert TE, Kashii Y, Gastman BR, Bell MC, Whiteside TL. (1998) Lymphocyte apoptosis induced by Fas ligand-expressing ovarian carcinoma cells. Implications for altered expression of $\mathrm{T}$ cell receptor in tumor-associated lymphocytes. J. Clin. Invest. 101: 2579-2588.

45. Uzzo RG, Rayman P, Kolenko V, et al. (1999) Mechanisms of apoptosis in $\mathrm{T}$ cells from patients with renal cell carcinoma. Clin. Cancer Res. 5: 1219-1229.

46. Zaks TZ, Chappell DB, Rosenberg SA, Restifo NP. (1999) Fas-mediated suicide of tumorreactive $\mathrm{T}$ cells following activation by specific tumor: selective rescue by caspase inhibition. J. Immunol. 162: 3273-3279.

47. Chappell DB, Zaks TZ, Rosenberg SA, Restifo NP. (1999) Human melanoma cells do not express Fas (Apo-1/CD95) ligand. Cancer Res. 59: 59-62.

48. O'Connell J, Bennett MW, O'Sullivan GC, Collins JK, Shanahan F. (1997) The Fas counterattack: a molecular mechanism of tumor immune privilege. Mol. Med. 3: 294-300.

49. Frost PJ, Belldegrun A, Bonavida B. (1999) Sensitization of immunoresistant prostate carcinoma cell lines to Fas/Fas ligand-mediated killing by cytotoxic lymphocytes: independence of de novo protein synthesis. Prostate 41: 20-30.

50. Ungefroren H, Voss $M$, Bernstorff WV, Schmid A, Kremer B, Kalthoff H. (1999) Immunological escape mechanisms in pancreatic carcinoma. Ann. NY Acad. Sci. 880: 243-251.

51. Shin EC, Shin JS, Park JH, Kim H, Kim SJ. (1999) Expression of Fas ligand in human hepatoma cell lines: role of hepatitis-B virus $\mathrm{X}$ (HBX) in induction of Fas ligand. Int. J. Cancer 82: 587-591.

52. Sakuma I, Yoshino T, Omonishi K, et al. (1999)
CD95 ligand is expressed in Reed-Sternberg cells of Hodgkin's disease. Pathol. Int. 49: 103-109.

53. Hahne M, Rimoldi D, Schroter M, et al. (1996) Melanoma cell expression of Fas(Apo-1/CD95) ligand: implications for tumor immune escape. Science 274: 1363-1366.

54. Whiteside TL. (1998) Immune cells in the tumor microenvironment. Mechanisms responsible for functional and signaling defects. Adv. Exp. Med. Biol. 451: 167-171.

55. Alexander J, Kudoh S, Melsop K, et al. (1993) $\mathrm{T}$ cells infiltrating renal cell carcinoma display a poor proliferative response even though they can produce IL-2 and express IL-2 receptors. Cancer Res. 53: 1380-1387.

56. Luscher U, Filgueira L, Juretic A, et al. (1994) The pattern of cytokine gene expression in freshly excised human metastatic melanoma suggests a state of reversible anergy of tumorinfiltrating lymphocytes. Int. J. Cancer 57: 612619.

57. Van den Hove LE, Van Gool SW, Van Poppel H, et al. (1997) Phenotype, cytokine production and cytolytic capacity of fresh (uncultured) tumour-infiltrating $\mathrm{T}$ lymphocytes in human renal cell carcinoma. Clin. Exp. Immunol. 109: 501509.

58. Angevin E, Kremer F, Gaudin C, Hercend T, Triebel F. (1997) Analysis of T-cell immune response in renal cell carcinoma: polarization to type 1-like differentiation pattern, clonal T-cell expansion and tumor-specific cytotoxicity. Int. J. Cancer 72: 431-440.

59. Lopez CB, Rao TD, Feiner H, Shapiro R, Marks JR, Frey AB. (1998) Repression of interleukin-2 mRNA translation in primary human breast carcinoma tumor-infiltrating lymphocytes. Cell. Immunol. 190: 141-155.

60. Vitolo D, Kanbour A, Johnson JT, Herberman RB, Whiteside TL. (1993) In situ hybridisation for cytokine gene transcripts in the solid tumour microenvironment. Eur. J. Cancer 3: 371-377.

61. Vitolo D, Zerbe T, Kanbour A, Dahl C, Herberman RB, Whiteside TL. (1992) Expression of mRNA for cytokines in tumor-infiltrating mononuclear cells in ovarian adenocarcinoma and invasive breast cancer. Int. J. Cancer 51: 573-580.

62. Camp B, Dyhrman S, Memoli V, Mott L, Barth R. (1996) In situ cytokine production by breast cancer tumor-infiltrating lymphocytes. Ann. Surg. Oncol. 3: 176-184.

63. Coventry B, Weeks S, Heckford S, Sykes P, Bradley J, Skinner J. (1996) Lack of IL-2 cytokine expression despite IL-2 messenger RNA transcription in tumor-infiltrating lymphocytes in primary human breast carcinoma. J. Immunol. 156: 3486-3492.

64. Pisa P, Halapi E, Pisa EK, et al. (1992) Selective expression of interleukin 10, interferon $\gamma$, and granulocyte-macrophage colony-stimulating 
factor in ovarian cancer biopsies. Proc. Natl. Acad. Sci. U.S.A. 89: 7708-7712.

65. Nakagomi H, Pisa P, Pisa EK, et al. (1995) Lack of interleukin-2 (IL-2) expression and selective expression of IL-10 mRNA in human renal cell carcinoma. Int. J. Cancer 63: 366-371.

66. Wang Q, Redovan C, Tubbs R, et al. (1995) Selective cytokine gene expression in renal cell carcinoma tumor cells and tumor-infiltrating lymphocytes. Int. J. Cancer 61: 780-785.

67. Rabinowich H, Suminami Y, Reichert TE, et al. (1996) Expression of cytokine genes or proteins and signaling molecules in lymphocytes associated with human ovarian carcinoma. Int. J. Cancer 68: 276-284.

68. Young MR, Wright MA, Lozano Y, Matthews JP, Benefield J, Prechel MM. (1996) Mechanisms of immune suppression in patients with head and neck cancer: influence on the immune infiltrate of the cancer. Int. J. Cancer 67: 333-338.

69. Zhang XL, Komada Y, Zhou YW, et al. (1997) Inhibition of interleukin-2 receptor (CD25) expression induced on $\mathrm{T}$ cells from children with acute lymphoblastic leukemia. Cancer Immunol. Immunother. 44: 41-47.

70. Itoh K, Tilden AB, Balch CM. (1986) Interleukin 2 activation of cytotoxic T-lymphocytes infiltrating into human metastatic melanomas. Cancer Res. 46: 3011-3017.

71. Whiteside TL, Heo DS, Chen K, Adler A, Johnson JT, Herberman RB. (1987) Expansion of tumor-infiltrating lymphocytes from human solid tumors in interleukin-2. Prog. Clin. Biol. Res. 244: 213-222.

72. Kudoh S, Redovan C, Rayman P, et al. (1997) Defective granzyme $B$ gene expression and lytic response in $\mathrm{T}$ lymphocytes infiltrating human renal cell carcinoma. J. Immunother. 20: 479-487.

73. Speiser DE, Miranda R, Zakarian A, et al. (1997) Self antigens expressed by solid tumors do not efficiently stimulate naive or activated T cells: implications for immunotherapy. $J$. Exp. Med. 186: 645-653.

74. Uslu R, Borsellino N, Frost P, et al. (1997) Chemosensitization of human prostate carcinoma cell lines to anti-fas-mediated cytotoxicity and apoptosis. Clin. Cancer Res. 3: 963-972.

75. Hishii M, Kurnick JT, Ramirez-Montagut T, Pandolfi F. (1999) Studies of the mechanism of cytolysis by tumour-infiltrating lymphocytes. Clin. Exp. Immunol. 116: 388-394.

76. Muzio M, Chinnaiyan AM, Kischkel FC, et al. (1996) FLICE, a novel FADD-homologous ICE/CED-3-like protease, is recruited to the CD95 (Fas/APO-1) death-inducing signaling complex. Cell 85: 817-827.

77. Gastman BR, Johnson DE, Whiteside TL, Rabinowich H. (1999) Caspase-mediated degradation of T-cell receptor $\zeta$-chain. Cancer Res. 59: 1422-1427.
78. Frydecka I, Kaczmarek P, Bocko D, Kosmaczewska A, Ciszak L. (1998) Alterations in signal transducing molecule $\mathrm{CD} 3 \zeta$ in patients with neoplastic diseases. Arch. Immunol. Ther. Exp. 46: 355-359.

79. Lai $\mathrm{P}$, Rabinowich H, Crowley-Nowick PA, Bell MC, Mantovani G, Whiteside TL. (1996) Alterations in expression and function of signaltransducing proteins in tumor-associated $\mathrm{T}$ and natural killer cells in patients with ovarian carcinoma. Clin. Cancer Res. 2: 161-173.

80. Kono K, Ichihara F, Iizuka H, Sekikawa T, Matsumoto Y. (1998) Expression of signal transducing T-cell receptor $\zeta$ molecules after adoptive immunotherapy in patients with gastric and colon cancer. Int. J. Cancer 78: 301-305.

81. Choi SH, Chung EJ, Whang DY, Lee SS, Jang YS, Kim CW. (1998) Alteration of signaltransducing molecules in tumor-infiltrating lymphocytes and peripheral blood T lymphocytes from human colorectal carcinoma patients. Cancer Immunol. Immunother. 45: 299-305.

82. Matsuda $\mathbf{M}$, Petersson $\mathbf{M}$, Lenkei $\mathbf{R}$, et al. (1995) Alterations in the signal-transducing molecules of T cells and NK cells in colorectal tumor-infiltrating, gut mucosal and peripheral lymphocytes: correlation with the stage of the disease. Int. J. Cancer 61: 765-772.

83. Finke JH, Zea AH, Stanley J, et al. (1993) Loss of T-cell receptor $\zeta$ chain and p56 $6^{\text {lck }}$ in T-cells infiltrating human renal cell carcinoma. Cancer Res. 53: 5613-5616.

84. Nakagomi H, Petersson M, Magnusson I, et al. (1993) Decreased expression of the signaltransducing $\zeta$ chains in tumor-infiltrating $\mathrm{T}$ cells and NK cells of patients with colorectal carcinoma. Cancer Res. 53: 5610-5612.

85. Nakanishi $H$, Monden $T$, Morimoto $H$, Kobayashi T, Shimano T, Mori T. (1991) Perforin expression in lymphocytes infiltrated to human colorectal cancer. Br. J. Cancer 64: 239-242.

86. Wakumoto Y, Sakamoto Y. (1993) [Immunohistochemical study on the expression of perforin in tumor infiltrating lymphocytes of renal cell carcinoma]. Nippon Hinyokika Gakkai Zasshi 84: 1759-1767.

87. Berg NN, Puente LG, Dawicki W, Ostergaard HL. (1998) Sustained TCR signaling is required for mitogen-activated protein kinase activation and degranulation by cytotoxic T lymphocytes. J. Immunol. 161: 2919-2924.

88. Wei S, Gamero AM, Liu JH, et al. (1998) Control of lytic function by mitogen-activated protein kinase/extracellular regulatory kinase 2 (ERK2) in a human natural killer cell line: identification of perforin and granzyme B mobilization by functional ERK2. J. Exp. Med. 187: 1753-1765.

89. Irmler $M$, Thome $M$, Hahne $M$, et al. (1997) Inhibition of death receptor signals by cellular FLIP. Nature 388: 190-195. 
90. Refaeli Y, Van Parijs L, London CA, Tschopp J, Abbas AK. (1998) Biochemical mechanisms of IL-2-regulated Fas-mediated T cell apoptosis. Immunity 8: 615-623.

91. Los M, Wesselborg S, Schulze-Osthoff K. (1999) The role of caspases in development, immunity, and apoptotic signal transduction: lessons from knockout mice. Immunity 10: 629-639.

92. Yeh JH, Hsu SC, Han SH, Lai MZ. (1998) Mitogen-activated protein kinase kinase antagonized fas-associated death domain protein-mediated apoptosis by induced FLICEinhibitory protein expression. J. Exp. Med. 188: 1795-1802.

93. Griffith TS, Wiley SR, Kubin MZ, Sedger LM, Maliszewski CR, Fanger NA. (1999) Monocyte-mediated tumoricidal activity via the tumor necrosis factor-related cytokine, TRAIL. J. Exp. Med. 189: 1343-1354.

94. Wiley SR, Schooley K, Smolak PJ, et al. (1995) Identification and characterization of a new member of the TNF family that induces apoptosis. Immunity 3: 673-682.

95. Nesic D, Jhaver KG, Vukmanovic S. (1997) The role of protein kinase $\mathrm{C}$ in $\mathrm{CD}^{+} \mathrm{T}$ lymphocyte effector responses. J. Immunol. 159: 582-590.

96. Fuller CL, Ravichandran KS, Braciale VL. (1999) Phosphatidylinositol 3-kinase-dependent and -independent cytolytic effector functions. J. Immunol. 162: 6337-6340.

97. Lilic M, Kulig K, Messaoudi I, et al. (2000) $\mathrm{CD}^{+} \mathrm{T}$ cell cytolytic activity independent of mitogen-activated protein kinase/extracellular regulatory kinase signaling. Eur. J. Immunol. 29: 3971-3977.

98. Marsigliante S, Biscozzo L, Marra A, et al. (1999) Computerised counting of tumour infiltrating lymphocytes in 90 breast cancer specimens. Cancer Lett. 139: 33-41.

99. Miescher S, Whiteside TL, Carrel S, Fliedner VV. (1986) Functional properties of tumorinfiltrating and blood lymphocytes in patients with solid tumors: effects of tumor cells and their supernatents on proliferative responses of lymphocytes. J. Immunol. 136: 1899-1907.

100. Whiteside TL, Miescher S, MacDonald HR, Von Fliedner V. (1986) Separation of tumorinfiltrating lymphocytes from tumor cells in human solid tumors. A comparison between velocity sedimentation and discontinuous density gradients. J. Immunol. Methods 90: 221- 233.

101. Haas GP, Solomon D, Rosenberg SA. (1990) Tumor-infiltrating lymphocytes from nonrenal urological malignancies. Cancer Immunol. Immunother. 30: 342-350.

102. Vesalainen $S$, Lipponen $P$, Talja $M$, Syrjanen K. (1994) Histological grade, perineural infiltration, tumour-infiltrating lymphocytes and apoptosis as determinants of long-term prognosis in prostatic adenocarcinoma. Eur. J. Cancer 12: 1797-1803.

103. Yoshino I, Yano T, Murata M, et al. (1992) Tumor-reactive $\mathrm{T}$ cells accumulate in lung cancer tissues but fail to respond due to tumor cell-derived factor. Cancer Res. 52: 775-781.

104. Vose BM, Vanky F, Klein E. (1977) Human tumour-lymphocyte interaction in vitro. V. Comparison of the reactivity of tumourinfiltrating, blood and lymph-node lymphocytes with autologous tumour cells. Int. J. Cancer 20: 895-902.

105. Hutchinson GH, Heinemann D, Symes MO, Williamson RC. (1981) Differential immune reactivity of tumour-intrinsic and peripheral-blood lymphocytes against autoplastic colorectal carcinoma cells. Br. J. Cancer 44: 396-402.

106. Bell MC, Edwards RP, Partridge EE, et al. (1995) $\mathrm{CD}^{+} \mathrm{T}$ lymphocytes are recruited to neoplastic cervix. J. Clin. Immunol. 15: 130136.

107. Takehara K. (1996) [Local immune responses in uterine cervical carcinogenesis]. Nippon Sanka Fujinka Gakkai Zasshi. 48: 1063-1070.

108. Guidoboni M, Doglioni C, Laurino L, Boiocchi M, Dolcetti R. (1999) Activation of infiltrating cytotoxic T lymphocytes and lymphoma cell apoptotic rates in gastric MALT lymphomas. Differences between high-grade and lowgrade cases. Am. J. Pathol. 155: 823-829.

109. Frisan T, Sjoberg J, Dolcetti R, et al. (1995) Local suppression of Epstein-Barr virus (EBV)specific cytotoxicity in biopsies of EBVpositive Hodgkin's disease. Blood 86: 14931501.

110. Vaccarello L, Kanbour A, Kanbour-Shakir A, Whiteside TL. (1993) Tumor-infiltrating lymphocytes from ovarian tumors of low malignant potential. Int. J. Gynecol. Pathol. 12: 41-50.

111. Biassoni R, Prigione I, Di Marco E, Ferrini S. (1985) Cytolytic activity of T lymphocytes isolated from ovarian carcinoma ascitic fluid. Analysis at the population and clonal level. Ric. Clin. Lab. 15: 177-183.

112. Ioannides CG, Platsoucas CD, Rashed $S$, Wharton JT, Edwards CL, Freedman RS. (1991) Tumor cytolysis by lymphocytes infiltrating ovarian malignant ascites. Cancer Res. 51: 4257-4265.

113. Finke JH, Tubbs R, Connelly B, Pontes E, Montie J. (1988) Tumor-infiltrating lymphocytes in patients with renal-cell carcinoma. Ann. N. Y. Acad. Sci. 532: 387-394.

114. Alexander $\mathrm{J}$, Rayman $\mathrm{P}$, Edinger $\mathrm{M}$, et al. (1990) TIL from renal-cell carcinoma: restimulation with tumor influences proliferation and cytolytic activity. Int. J. Cancer 45: 119-124. 
115. Weidmann E, Whiteside TL, Giorda R, Herberman RB, Trucco M. (1992) The T-cell receptor $\mathrm{V} \beta$ gene usage in tumor-infiltrating lymphocytes and blood of patients with hepatocellular carcinoma. Cancer Res. 52: 5913-5920.

116. Wang Y, Chen H, Wu M, Bao J, Cong W, Wang H. (1997) Postoperative immunotherapy for patients with hepatocarcinoma using tumorinfiltrating lymphocytes. Chin. Med. J. 110: 114-117.

117. Nakao M, Sata M, Saitsu H, et al. (1997) CD4 ${ }^{+}$ hepatic cancer-specific cytotoxic $\mathrm{T}$ lymphocytes in patients with hepatocellular carcinoma. Cell. Immunol. 177: 176-181.

118. Yoong KF, McNab G, Hubscher SG, Adams DH. (1998) Vascular adhesion protein-1 and ICAM-1 support the adhesion of tumor-infil- trating lymphocytes to tumor endothelium in human hepatocellular carcinoma. J. Immunol. 160: 3978-3988.

119. Shimizu Y, Watanabe A, Whiteside TL. (1992) Memory T-lymphocytes are the main population of tumor-infiltrating lymphocytes obtained from human primary liver tumors. J. Hepatol. 16: 197-202.

120. Bodey B, Bodey B, Siegel SE, Luck JV, Kaiser HE. (1996) Immunophenotypic characterization of human primary and metastatic melanoma infiltrating leukocytes. Anticancer Res. 16: 3439-3446.

121. Anichini A, Fossati G, Parmiani G. (1985) Clonal analysis of cytotoxic T-lymphocyte response to autologous human metastatic melanoma. Int. J. Cancer 35: 683-689. 